\title{
Subsidence after total lumbar disc replacement is predictable and related to clinical outcome
}

\author{
J. Kitzen ${ }^{1}$ (D) V. Verbiest ${ }^{2}$ - I. Buil ${ }^{3} \cdot$ M. G. M. Schotanus ${ }^{3}$ B. van Rietbergen ${ }^{2} \cdot$ S. M. J. van Kuijk ${ }^{4}$ L. W. van Rhijn ${ }^{1}$. \\ P. C. P. H. Willems ${ }^{1}$
}

Received: 20 March 2020 / Revised: 16 April 2020 / Accepted: 29 April 2020 / Published online: 23 May 2020

(c) The Author(s) 2020

\begin{abstract}
Purpose As yet, there are no studies describing a relationship between radiographic subsidence after lumbar total disc replacement (TDR) and patient symptoms. To investigate if subsidence, in terms of penetrated bone volume or angular rotation over time ( $\triangle \mathrm{PBV}$ and $\triangle \mathrm{AR}$ ), is related to clinical outcome. To assess if subsidence can be predicted by position implant asymmetry (IA) or relative size of the TDR, areal undersizing index (AUI) on direct post-operative radiographs.

Methods Retrospective cohort study consists of 209 consecutive patients with lumbar TDR for degenerative disc disease. A three-dimensional graphical representation of the implant in relation to the bony endplates was created on conventional radiographs. Consequently, the PBV, AR, IA and AUI were calculated, direct post-operative (DPO) and at last follow-up (LFU). For clinical evaluation, patients with substantial pain (VAS $\geq 50)$ and malfunction $(\mathrm{ODI} \geq 40)$ were considered failures.

Results At a mean follow-up of 16.7 years, 152 patients (73\%) were available for analysis. In 32 patients, revision by spinal fusion had been performed. Both $\Delta \mathrm{AR}\left(4.33^{\circ}\right.$ vs. $\left.1.83^{\circ}, p=0.019\right)$ and $\Delta \mathrm{PBV}\left(1448.4 \mathrm{~mm}^{3}\right.$ vs. $\left.747.3 \mathrm{~mm}^{3}, p=0.003\right)$ were significantly higher in the failure-compared to the success-group. Using ROC curves, thresholds for symptomatic subsidence were defined as $\triangle \mathrm{PBV} \geq 829 \mathrm{~mm}^{3}$ or PBV-LFU $\geq 1223 \mathrm{~mm}^{3}$ [area under the curve (AUC) $0.723, p=0.003$ and 0.724 , $p=0.005$, respectively]. Associations between symptomatic subsidence and AUI-DPO $\geq 0.50$ (AUC $0.750, p=0.002$ ) and AR-DPO $\geq 3.95^{\circ}$ (AUC 0.690, $p=0.022$ ) were found.

Conclusion Subsidence of a TDR is associated with a worse clinical outcome. The occurrence of subsidence is higher in case of incorrect placement or shape mismatch.
\end{abstract}

Keywords Degenerative disc disease $\cdot$ Chronic low back pain $\cdot$ Lumbar spine $\cdot$ Total disc replacement $\cdot$ Malposition · migration or subsidence

\section{Introduction}

Fusion of a symptomatic lumbar spinal motion segment is the most commonly used operative treatment for patients with degenerative disc disease (DDD) not responding to

J. Kitzen

j.kitzen@mumc.nl

1 Department of Orthopedic Surgery, Maastricht University Medical Centre, Maastricht, The Netherlands

2 Department of Biomedical Engineering, Eindhoven University of Technology, Eindhoven, The Netherlands

3 Department of Orthopedic Surgery, Zuyderland Medical Centre, Sittard-Geleen, The Netherlands

4 Department of Clinical Epidemiology, Maastricht University Medical Centre, P.O. Box 5800, 6202 AZ Maastricht, The Netherlands conservative care [1]. However, spinal fusion is associated with negative side effects such as proximal facet-joint violation, pseudarthrosis and symptomatic adjacent level disease (ASD) [2-9]. In order to avoid those fusion-related side effects, lumbar total disc replacement (TDR) has been introduced. However, TDR has also been associated with drawbacks, such as subsidence, dislocation, or malposition of the implant [10-12].

Subsidence of a TDR, defined as the penetration of the prosthetic endplate into the vertebral endplate (Fig. 1), is a frequently documented complication [10, 11, 13-16]. 


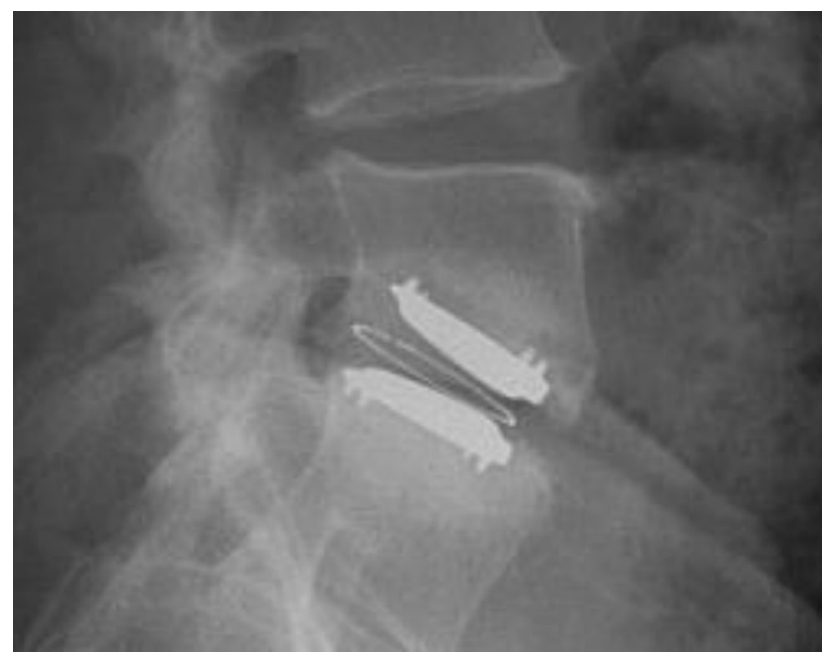

Fig. 1 An example of subsidence

Subsidence occurs presumably due to non-central implantation [17, 18], implant undersizing [19, 20], or reduced bone quality [21]. It may ultimately lead to spontaneous fusion of the vertebral segment or to failure of the TDR [14, 22]. Consequently, patients with symptoms and radiographic subsidence, even without clear signs of wear and/or displacement, may undergo revision surgery [22]. However, there are no studies describing the relation between the occurrence of subsidence and signs or symptoms of the patient.

The purpose of this study was to investigate to what extent subsidence of the TDR is related to clinical outcome. A secondary goal was to investigate if subsidence could be predicted by the position and relative size of the TDR on the direct post-operative radiographs.

\section{Material and methods}

\section{Patient selection}

The current study was approved by the local medical ethics committee METC Z (16-N-22) and registered at the Dutch Trial Registry (NTR5710). The medical records of all patients who underwent a TDR using an SB Charité III (Waldemar Link, Germany; DePuy Spine, Raynham, MA) between 1994 and 2000 (in 1998 a bioactive hydroxyapatite coating of the prosthetic endplates was introduced) at the Zuyderland Medical Centre, Sittard, The Netherlands, were reviewed.

TDR had been performed by a single surgeon for the treatment of patients with lumbar DDD, causing predominant axial low back pain. Care was taken intra-operatively, to avoid violation of the bony endplate by the implant. The diagnosis was based on plain standing radiographs of the lumbar spine taken in antero-posterior (AP) and lateral views. Preoperatively, all patients had undergone fluoroscopically guided provocation discography to confirm a painful disc. No facet joint injections had been performed. Nerve root compression and/or spinal stenosis was considered as a contraindication for TDR. All patients were contacted with the request to visit the outpatient clinic for clinical evaluation and AP and lateral radiographs.

\section{Radiological analysis}

\section{Subsidence as assessed by penetrated bone volume}

A custom developed and validated software package implemented in MATLAB (MATLAB R2017b, Mathworks, MA) was used to create a three-dimensional graphical representation of the implant [20]. By projecting the prosthetic endplate on the plane representing the vertebral endplate, the penetrated bone volume (PBV) was calculated in $\mathrm{mm}^{3}$ (Fig. 2). The dimensions (width/length) of the prosthetic endplate were based on the size of the circular polyethylene insert, as documented in the patient's operative records. The prosthetic endplate was represented by parabolic functions for the anterior/posterior sides. This resulted in a shape that well-matches the actual endplate (Fig. 3). The PBV was calculated simultaneously for both the upper and lower part of the TDR, and these values were added together.

\section{Subsidence as assessed by angular rotation (AR)}

A second custom-developed software package implemented in MATLAB was used to simultaneously display AP and lateral radiographs, direct post-operative and at last followup. On both the AP and lateral image, the angle between the prosthetic and the vertebral endplate was calculated for the upper and lower part of the prosthesis (Fig. 4), using Cobb's method [23, 24]. The highest value (upper- or lower part) was used for this analysis [15]. Analyses were done for the direct post-operative and for the last follow-up radiographs. The differences $(\Delta)$ between the AR at last follow-up and direct post-operative (upper- and lower part) for each individual patient were calculated. The highest value was used for this analysis.

\section{Areal Undersizing Index (AUI)}

Using the same custom MATLAB software package, the potential mismatch between the surface area of the vertebral $\left(A_{\text {vertebra }}\right)$ and the prosthetic endplate area $\left(A_{\mathrm{TDR}}\right)$ was determined (Fig. 5). For this analysis, the vertebra and the prosthesis were assumed to be parabolic, and the surface 


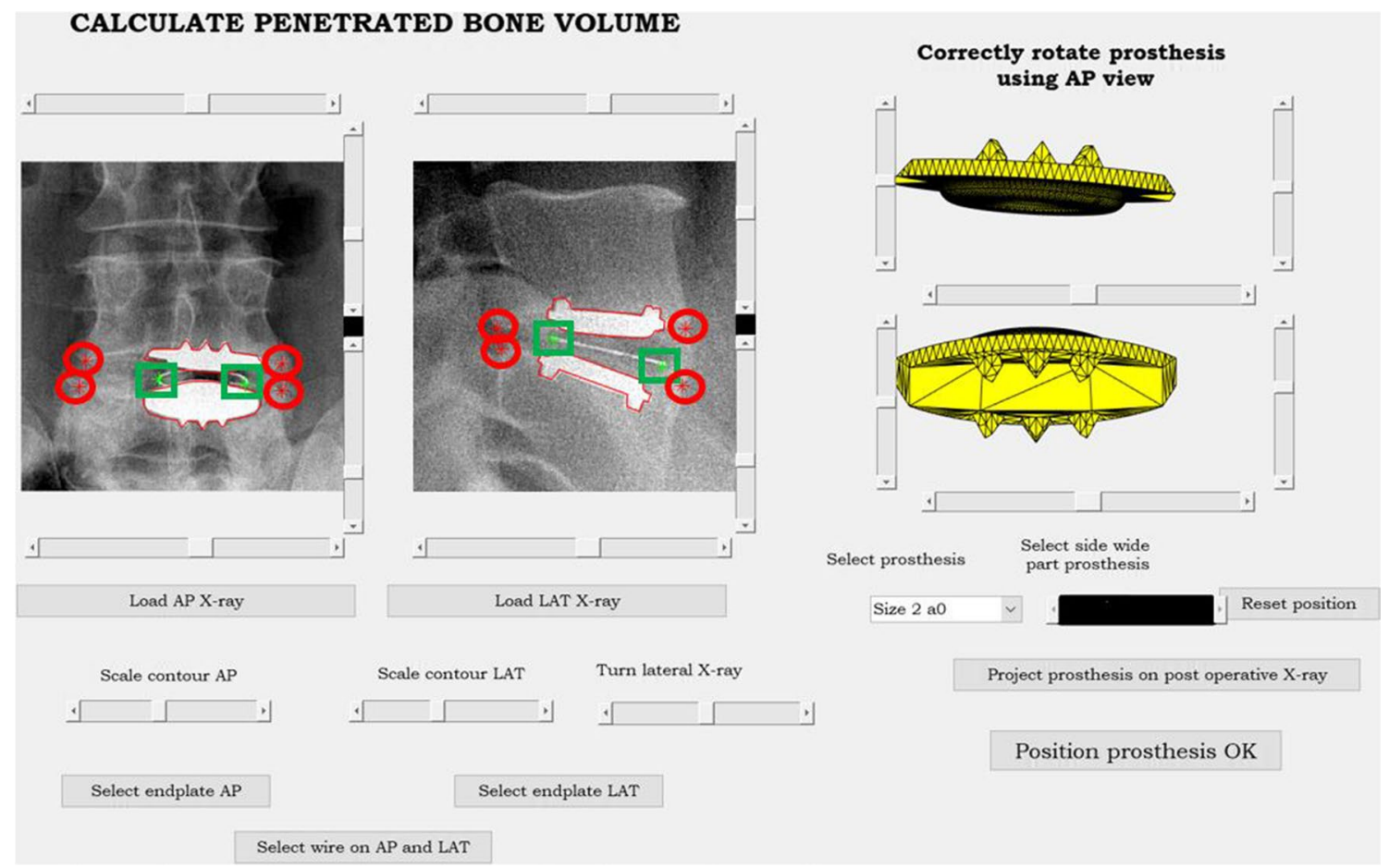

Fig. 2 Three-dimensional graphical representation of the TDR implant in relation to the bony endplates. This representation can be rotated manually until its contour best replicates the outline of the implant on both AP and lateral radiographs. Next, the most lateral left and right points of the bony endplate on the AP radiograph and the most anterior and posterior points of the bony endplate on the lat-

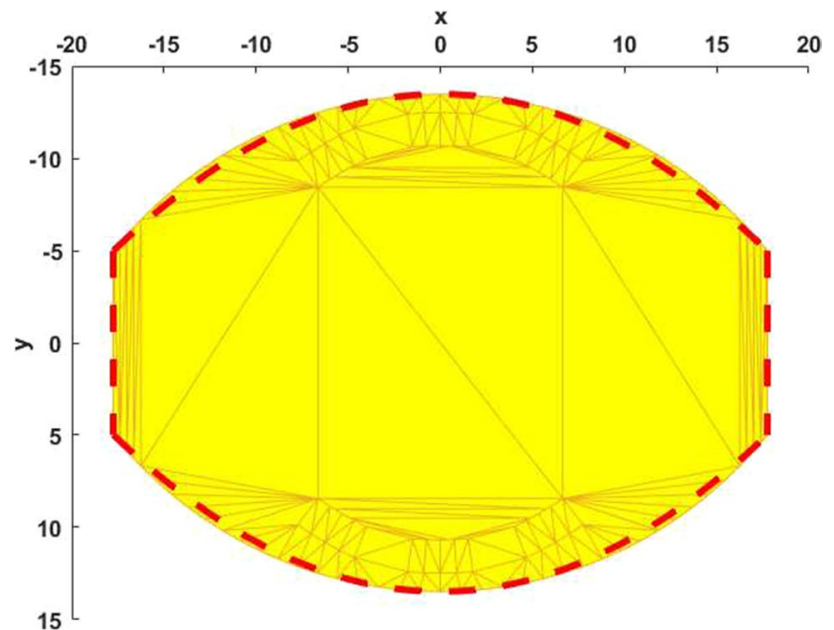

Fig. 3 Bottom view of the graphical TDR representation, where the red lines indicates the contour of the used surface for calculating the PBV

area was calculated as: $A=\pi * a * b$ for both the vertebrae $\left(A_{\text {vertebrae }}\right)$ and TDR $\left(A_{\mathrm{TDR}}\right)$. Subsequently, the AUI was determined on the upper and the lower part of the eral radiograph were identified (red circles). Similar points had to be indicated on the metal ring of the circular polyethylene insert (green squares). The latter were used to correct for the difference in magnification factor between the AP and lateral radiograph of the same patient

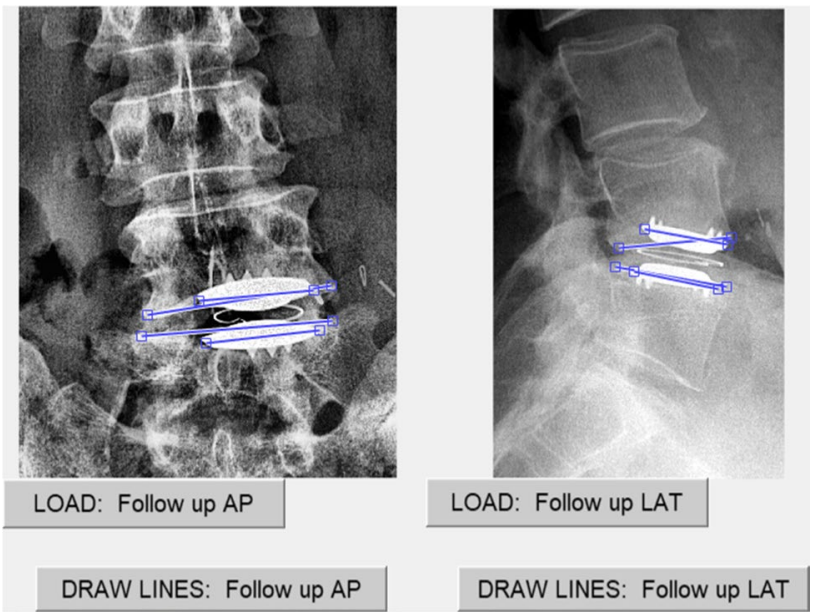

Fig. 4 Angular rotation between the vertebral and prosthetic endplate on an AP and LAT radiograph

prosthesis. The highest value (least coverage) was used for the analysis. 


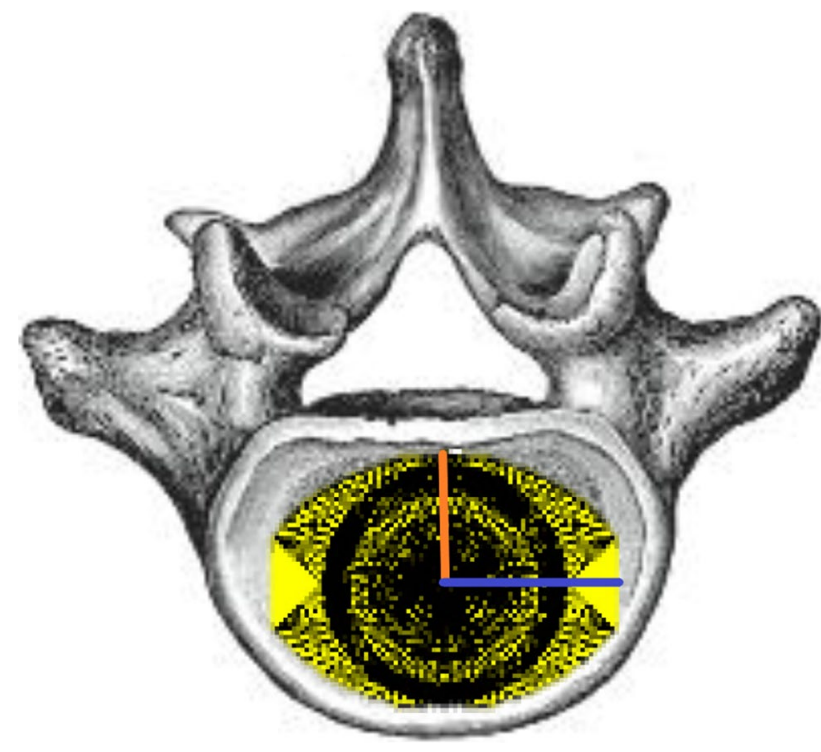

Fig. 5 Representation of the semi-major axis (blue line) and semiminor axis (orange line) of the ellipse fitted around the prosthesis

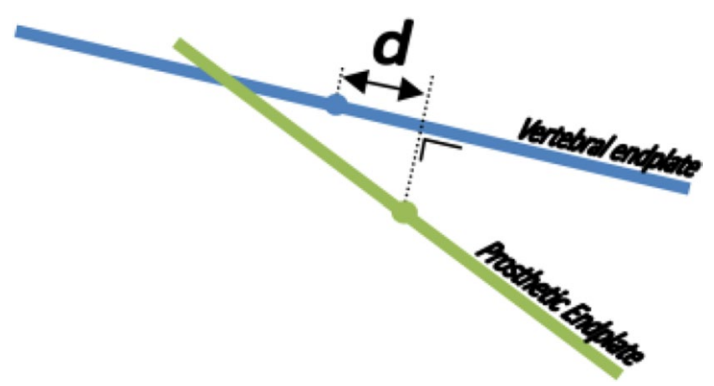

Fig. 6 Implant asymmetry in percentage is the shortest distance $(d)$ between the middle of both the vertebral and the prosthetic endplate, divided by the corresponding vertebral endplate diameter (blue line)

Areal Undersizing Index $=\frac{A_{\text {vertebra }}-A_{\mathrm{TDR}}}{A_{\text {vertebra }}}$.

A value of zero implies that the contour of the TDR is perfectly matched with the contour of the vertebrae, whereas a large value indicates undersizing of the implant.

\section{Implantation asymmetry}

Using the same MATLAB package, implantation asymmetry (IA) was defined as the shortest distance $(d)$ between the middle of both the vertebral and the prosthetic endplate (Fig. 6), divided by the corresponding vertebral endplate diameter. The measurements were done for the upper and lower part of the TDR, and the highest value was used for the analysis. The differences $(\Delta)$ between the IA at last follow-up and direct post-operative (upper- and lower part) for each individual patient were calculated. The highest value was used for this analysis.

A value of zero implies that the prosthesis is perfectly aligned with the vertebrae, whereas a large value indicates a translation from the centre. These values were measured on both the AP and lateral radiographs such that the symmetry can be quantified in two directions.

\section{Clinical outcome evaluation}

At last follow-up, back- and leg-pain intensity was recorded in all patients with a Visual Analog Scale (VAS, 0 to 100, 100 being 'worst pain'). The highest value was used for the analysis. Functional well-being was evaluated using Oswestry Disability Index (ODI, 0 to 100, 100 being maximally disabled).

\section{Data analysis and statistics}

All radiological measurements were performed by two independent observers, who were not involved in patient care $(\mathrm{JK}, \mathrm{VV})$. Mean values of their measurements were calculated. The interclass correlation coefficient (ICC) was used to quantify agreement between the two observers.

Patients were assigned to a success or failure group based on their reported VAS and ODI score (failure was defined as VAS $\geq 50$ in combination with an ODI $\geq 40$ ) $[16,25]$. In addition, patients with a revision by spinal fusion were included if both the radiographs direct post-operative and before their revision were available. They were all considered as failures of the TDR. The independent samples $t$ test was used to test for differences in the means of the radiological parameters between both groups. Using receiver operating characteristic (ROC) curves, possible threshold values were analyzed. A cut-off $p$ value of $<0.05$ was considered statistically significant. All analyses were performed using IBM SPSS (Version 23.0).

\section{Results}

\section{Study population}

Altogether 225 patients who had undergone a TDR at level L4-L5 and/or L5-S1 were identified, 16 patients had deceased $(7.1 \%)$. The remaining 209 patients were contacted by mail and subsequently by phone, with the request to visit our outpatient clinic. A total of 152 patients $(72.7 \%)$ were available for analysis. In 32 patients (15.3\%), a revision by spinal fusion had been performed prior to our study. In only five patients, this revision was because of subsidence or 
malposition of the implant. In the remaining patients, the reason for revision was facet joint degeneration $(n=14)$, ASD $(n=10)$, or dislocation of the implant $(n=3)$. In eight out of these 32 patients, a complete set of radiographs was available and they were included for analysis. Informed consent was acquired in all patients.

Mean follow-up after implantation was 16.7 years (median 16.4, range 13.6-23.0 years). In 18 patients (15.0\%), the direct post-operative radiographs were not available. The remaining 102 patients were included for radiological analysis. Patient characteristics are listed in Table 1. Due to overprojection of the pelvis on the AP radiographs, for patients

Table 1 Summary of subgroup patient demographic and surgical data presented as mean (standard deviation) or proportions (\%)

\begin{tabular}{ll}
\hline & Patients $(n=128)$ \\
\hline Males, number & $58(45.3)$ \\
Mean age at time of surgery in years & $42.6(7.3)$ \\
Previous spinal surgery & $24(18.8)$ \\
Surgical levels & \\
L2-L3 & $1(0.8)$ \\
L3-L4 & $2(1.7)$ \\
L4-L5 & $64(50.0)$ \\
L5-S1 & $78(60.9)$ \\
Number of levels (one: two) & $111: 17$ \\
Indication for lumbar disc replacement $(n=125)$ & \\
DDD without any other accompanying patholo- & $91(72.8)$ \\
$\quad$ gies & \\
DDD with a disc herniation and predominant & $19(15.2)$ \\
$\quad$ axial low back pain & $15(12.0)$ \\
DDD following a discectomy &
\end{tabular}

with a single TDR at L5-S1, the PBV, AUI and IA-AP could not be determined $(n=56)$. Consequently, in 110 patients, the AR and IA-LAT and in 54 patients the PBV, AUI and IA-AP could be determined. In only four patients, a dualenergy X-ray absorptiometry (DEXA) scan was available, hence we were unable to report on bone mineral density in relation to the occurrence of subsidence.

\section{Radiological analysis in relation to clinical outcome}

High ICC between the two observers were found for AR $(R \geq 0.90, p<0.01)$, IA $(R \geq 0.88, p<0.01)$, AUI $(R \geq 0.85$, $p<0.01)$ and especially PBV $(R \geq 0.972, p<0.01)$. As shown in Table 2, there was a significant difference for AR $\left(5.58^{\circ}\right.$ vs. $\left.6.80^{\circ}, p=0.047\right)$, but no significant differences in the mean values for AR, IA, PBV and AUI direct postoperative (DPO) between the success $(N=61)$ and failure group $(N=49)$. At last follow-up (LFU), both the AR $\left(8.89^{\circ}\right.$ vs. $\left.6.51^{\circ}, p=0.019\right)$ and PBV $\left(1757.2 \mathrm{~mm}^{3}\right.$ vs. $1058.7 \mathrm{~mm}^{3}$, $p=0.003$ ) were significantly higher in the failure compared to the success group. When the differences for the mean values between LFU and DPO were calculated, again for $\mathrm{AR}\left(\Delta \mathrm{AR}, 4.33^{\circ}\right.$ vs. $1.83^{\circ}$ for the failure and success groups, respectively, $p=0.001)$ and $\mathrm{PBV}\left(\Delta \mathrm{PBV}, 1448.4 \mathrm{~mm}^{3}\right.$ vs. $747.3 \mathrm{~mm}^{3}$ for the failure and success groups, respectively, $p=0.003$ ) a significant difference was observed. Both PBVLFU and $\triangle \mathrm{PBV}$ were significantly higher in patients with a revision, compared to those in the success group $(p=0.009$ and $p=0.001$, respectively). No significance differences, between the patients with $(n=68)$ or without (42) the porous coating of the endplates, were observed.

Table 2 Mean values (standard deviation) of the success and failure group and the differences (95\% confidence interval) between the two groups

\begin{tabular}{|c|c|c|c|c|c|}
\hline & $N$ & Success group $(N=61)$ & Failure group $(N=49)$ & Differences $(\Delta)$ & $p$ value $^{\mathrm{a}}$ \\
\hline AR post-operative & 110 & $5.57^{\circ}(3.34)$ & $6.80^{\circ}(2.94)$ & $1.22(-0.19$ to 2.42$)$ & 0.047 \\
\hline AR at follow-up & & $6.51^{\circ}(4.14)$ & $8.89^{\circ}(5.92)$ & $2.37(0.49$ to 4.35$)$ & 0.019 \\
\hline $\mathrm{AR}$ increase $(\Delta \mathrm{AR})$ & & $1.83^{\circ}(1.83)$ & $4.33^{\circ}(4.39)$ & 2.50 (1.14 to 3.87$)$ & 0.001 \\
\hline IA LAT post-operative & 110 & $6.67 \%(4.85)$ & $6.75 \%(7.88)$ & 0.08 ( -2.40 to 2.61$)$ & 0.934 \\
\hline IA LAT at follow-up & & $7.01 \%(4.66)$ & $6.37 \%(4.58)$ & $-0.64(-2.49$ to 1.22$)$ & 0.496 \\
\hline IA LAT increase & & $3.03 \%(2.42)$ & $4.11 \%(6.79)$ & 1.08 ( -0.80 to 2.96$)$ & 0.256 \\
\hline PBV post-operative & 54 & $311.4 \mathrm{~mm}^{3}(542.8)$ & $308.8 \mathrm{~mm}^{3}(555.3)$ & $-2.62(-295.0$ to 289.9$)$ & 0.986 \\
\hline PBV at follow-up & & $1058.7 \mathrm{~mm}^{3}(890.3)$ & $1757.2 \mathrm{~mm}^{3}(951.0)$ & 698.5 (195.6 to 1201.3$)$ & 0.007 \\
\hline PBV increase $(\Delta \mathrm{PBV})$ & & $747.3 \mathrm{~mm}^{3}(736.7)$ & $1448.4 \mathrm{~mm}^{3}(913.9)$ & $701.0(249.0$ to 1153.1$)$ & 0.003 \\
\hline IA AP post-operative & 54 & $4.84 \%(2.98)$ & $6.39 \%(4.59)$ & $1.55(-0.62$ to 3.71$)$ & 0.157 \\
\hline IA AP at follow-up & & $4.87 \%(3.10)$ & $8.09 \%(9.50)$ & $3.22(-0.72$ to 7.16$)$ & 0.107 \\
\hline IA AP increase & & $1.93 \%(1.22)$ & $3.40 \%(7.05)$ & $1.47(-1.35$ to 4.29$)$ & 0.299 \\
\hline AUI post-operative & 54 & $0.50(0.06)$ & $0.53(0.06)$ & $0.03(-0.01$ to 0.06$)$ & 0.132 \\
\hline
\end{tabular}

$A R$ angular rotation, $I A$ implant asymmetry, $P B V$ penetrated bone volume, $A U I$ Area Undersizing Index

andependent $t$ test

Bold values indicate that the statically significant differences 
Table 3 ROC curve association for failure presented as the area under the curve (standard error)

\begin{tabular}{lllll}
\hline & $N$ & Area under the curve & Optimal cut-off value & $p$ value \\
\hline AR post-operative & 110 & $\mathbf{0 . 6 2 9}(\mathbf{0 . 0 5 3})$ & $\mathbf{4 . 3 5}^{\circ}$ & $\mathbf{0 . 0 2 1}$ \\
AR at follow-up & & $\mathbf{0 . 6 2 5}(\mathbf{0 . 0 5 4})$ & $\mathbf{6 . 2 3}^{\circ}$ & $\mathbf{0 . 0 2 6}$ \\
AR increase $(\Delta \mathrm{AR})$ & & $\mathbf{0 . 6 8 5}(\mathbf{0 . 0 5 4})$ & $\mathbf{1 . 8 5}^{\circ}$ & $\mathbf{0 . 0 0 1}$ \\
IA LAT post-operative & 110 & $0.514(0.058)$ & $\mathrm{NA}$ & 0.811 \\
PBV post-operative & 54 & $0.509(0.081)$ & $\mathrm{NA}$ & 0.910 \\
PBV at follow-up & & $\mathbf{0 . 7 2 4}(\mathbf{0 . 0 6 9})$ & $\mathbf{1 2 2 3} \mathbf{~ m m}^{3}$ & $\mathbf{0 . 0 0 5}$ \\
PBV increase $(\Delta \mathrm{PBV})$ & & $\mathbf{0 . 7 3 2}(\mathbf{0 . 0 6 8})$ & $\mathbf{8 2 9} \mathbf{~ m m}^{3}$ & $\mathbf{0 . 0 0 3}$ \\
IA AP post-operative & 54 & $0.592(0.084)$ & $\mathrm{NA}$ & 0.262 \\
AUI post-operative & 54 & $0.638(0.078)$ & $\mathrm{NA}$ & 0.092 \\
\hline
\end{tabular}

$A R$ angular rotation, $I A$ implant asymmetry, $P B V$ penetrated bone volume, $A U I$ Area Undersizing Index Bold values indicate that the statically significant differences
Subsequently, ROC curves were plotted for the occurrence of failure in relation to AR, IA, AUI or PBV. Possible threshold values were determined by minimizing the false positive and false negative classifications (Table 3). A threshold of $6.23^{\circ}$ was obtained for AR-LFU [area under the curve (AUC) 0.625, $p=0.026]$. For $\Delta \mathrm{AR}$, an increase over time of $1.85^{\circ}$ (AUC $0.685, p=0.001$ ) was associated with failure. For PBV-LFU, a threshold of $1223 \mathrm{~mm}^{3}$ (AUC $0.724, p=0.005$ ) was determined and for $\triangle \mathrm{PBV}$ an increase of $829 \mathrm{~mm}^{3}$ (AUC 0.723 , $p=0.003$ ) was established. For IA and AUI, no significant associations were seen. When applying these thresholds for PBV, 27 (54.0\%, PBV-LFU) and $23(46.0 \%, \Delta \mathrm{PBV})$ of the studied patients without a revision $(N=51)$ have radiographic subsidence.

\section{Subsidence in relation to the position and relative size of the TDR}

To investigate whether subsidence could be predicted by the position and relative size of the TDR on the direct post-operative radiographs, we also investigated associations between position as measured from these radiographs and symptomatic subsidence as outcome. We defined symptomatic subsidence as a PBV-LFU of $\geq 1223 \mathrm{~mm}^{3}$ or a $\triangle \mathrm{PBV}$ of $\geq 829$ $\mathrm{mm}^{3}$, since both threshold values displayed the largest AUC. In addition, both can detect parallel subsidence, in contrary to $\triangle \mathrm{AR}$. In seven patients (6.4\%), a $\triangle \mathrm{PBV}$ of $\geq 829 \mathrm{~mm}^{3}$ with a $\triangle \mathrm{AR}<1.85^{\circ}$, indicative for parallel subsidence, was observed. ROC curves were plotted for both PBV-LFU (Table 4) and for $\triangle \mathrm{PBV}$ (Table 5) in relation to AR, IA and AUI measured direct post-operatively.

The occurrence of symptomatic subsidence defined as a PBV-LFU of $\geq 1223 \mathrm{~mm}^{3}$ is associated with an AR-DPO of $\geq 3.96^{\circ}$ (AUC 0.690, $p=0.022$ ) and with an AUI-DPO of $>0.50$ (AUC 0.750, $p=0.002$ ). When the occurrence of symptomatic subsidence was defined as a $\triangle \mathrm{PBV}$ of $\geq 829$ $\mathrm{mm}^{3}$, only an association with an AUI-DPO of $<0.51$ (AUC
Table 4 ROC curve predictors for subsidence defined as a penetrated bone volume at follow-up $\geq 1223 \mathrm{~mm}^{3}$ presented as the area under the curve (standard error)

\begin{tabular}{|c|c|c|c|c|}
\hline & $N$ & $\begin{array}{l}\text { Area under the } \\
\text { curve }\end{array}$ & $\begin{array}{l}\text { Optimal } \\
\text { cut-off } \\
\text { value }\end{array}$ & $p$ value \\
\hline AR post-operative & 110 & $0.690(0.075)$ & $3.96^{\circ}$ & 0.022 \\
\hline $\begin{array}{l}\text { IA LAT post- } \\
\text { operative }\end{array}$ & 110 & $0.612(0.080)$ & NA & 0.176 \\
\hline $\begin{array}{l}\text { IA AP post-oper- } \\
\text { ative }\end{array}$ & 54 & $0.501(0.084)$ & NA & 0.992 \\
\hline AUI post-operative & 54 & $0.750(0.074)$ & $\mathbf{0 . 5 0}$ & 0.002 \\
\hline
\end{tabular}

$A R$ angular rotation, $I A$ implant asymmetry, $A U I$ Area Undersizing Index

Bold values indicate that the statically significant differences

Table 5 ROC curve predictors for subsidence defined as a $\Delta$ Penetrated Bone Volume at follow $\geq 829 \mathrm{~mm}^{3}$ presented as the area under the curve (standard error)

\begin{tabular}{lrlll}
\hline & $N \quad \begin{array}{l}\text { Area under the } \\
\text { curve }\end{array}$ & $\begin{array}{l}\text { Optimal } \\
\text { cut-off } \\
\text { value }\end{array}$ & $p$ value \\
\hline $\begin{array}{l}\text { AR post-operative } \\
\begin{array}{l}\text { IA LAT post-oper- } \\
\text { ative }\end{array}\end{array}$ & 110 & $0.597(0.081)$ & NA & $0.596(0.082)$ \\
$\begin{array}{l}\text { IA AP post-oper- } \\
\text { ative }\end{array}$ & 54 & $0.539(0.084)$ & NA & 0.247 \\
AUI post-operative & 54 & $\mathbf{0 . 7 1 8}(\mathbf{0 . 0 7 3})$ & $\mathbf{N A}$ & 0.633 \\
\hline
\end{tabular}

$A R$ angular rotation, $I A$ implant asymmetry, $A U I$ Area Undersizing Index

Bold values indicate that the statically significant differences

$0.718, p=0.008$ ) was determined. For IA no significant associations were seen. 


\section{Discussion}

This study represents a long-term follow-up of patients after lumbar TDR for the treatment of symptomatic DDD, and is the first study to establish a clear relation between the occurrence of radiographic subsidence and signs or symptoms of patients. Furthermore, the occurrence of subsidence could be predicted by the AR and AUI of the TDR measured on the direct post-operative radiographs. High ICC between the two observers was found, indicating high agreement between observers.

Subsidence may ultimately lead to spontaneous fusion of the vertebral segment or to failure of the TDR due to wear or displacement [14]. To quantify radiographic subsidence, different methods have previously been described. Lee et al. defined subsidence as an increase over time of $5^{\circ}$ in AR, measured on lateral radiographs [15]. They found no significant difference in clinical outcome between the patients with or without subsidence. However, parallel subsidence cannot be detected using this method. In the present study, we identified seven patients $(6.4 \%)$ with parallel subsidence.

Punt et al. [20] considered radiographic subsidence to be present if the PBV-LFU was more than $1300 \mathrm{~mm}^{3}$ or if the PBV-LFU was between 700 and $1300 \mathrm{~mm}^{3}$ in combination with an AR of more than $7.5^{\circ}$. These values are similar with our findings. However, in contrast to the current study, no direct post-operative images were available. Consequently, they could not investigate whether initial malpositioning or migration over time of the implant had led to the apparent radiographic subsidence at last follow-up. In addition, no clinical outcomes were reported, so they could not look for an association between the occurrence of subsidence and signs or symptoms.

\section{Radiographic subsidence in relation to clinical outcome}

In the current study, we determined that at last followup both the AR and PBV were significantly higher in the failure group (VAS $\geq 50$ and ODI $\geq 40$ ). This also applies when the differences between the mean values at last follow-up and direct post-operative were calculated $(\Delta \mathrm{AR}$ and $\triangle \mathrm{PBV})$. It must be noted that $40.2 \%$ of the patients $(n=41)$ were classified as failures based on their clinical outcome, a number exceeding the number of patients with a revision in our population $(n=32)$. However, these findings indicate that there is a relation between the occurrence of radiographic subsidence in terms of PBV and AR and signs or symptoms of the patient. Having established this, performing revision surgery for patients with radiographic subsidence and signs or symptoms seems a more viable option. This finding does not imply that worse clinical outcome is exclusively due to radiographic subsidence in all patients. Using ROC curves, clinically applicable threshold values $\left(\triangle \mathrm{PBV} \geq 829 \mathrm{~mm}^{3}\right.$ or PBV-LFU $\geq 1223$ $\mathrm{mm}^{3}$ ) were obtained to assess which patients are at risk for symptomatic subsidence and were most likely to benefit from revision surgery.

\section{Symptomatic subsidence in relation to the position and relative size of the TDR}

ROC curves were plotted, to investigate whether symptomatic subsidence could be predicted by the position and relative size of the TDR on the direct post-operative radiographs. It seems that the AR should not exceed $4^{\circ}$. In addition, a reduced risk of symptomatic subsidence was found if at least $50 \%$ of the area of the bony endplate of the vertebra was covered by the TDR endplate. This value is consistent although slightly lower than the $60 \%$ described by Punt et al. [20]. We believe that our threshold is a better representation because in the current study, not only patients with clinical problems after receiving TDR were included, but also asymptomatic patients, and a correlation with clinical outcome was established.

Initially, the relation between implant size and failure of the TDR was emphasized not enough. Gstoettner et al. reported a maximum allowed distance of $5 \mathrm{~mm}$, between the edges of the TDR- and vertebral endplates on either side on both AP an lateral views, to prevent subsidence [19]. In the current study, mainly (98\%) size $2(25-31.5 \mathrm{~mm})$ to 4 (29-38.5 mm) of the Charité III lumbar TDR were inserted. We can calculate the AUI when applying their method for the different sizes using the product specifications. Doing so, for size 2 an AUI of 0.46 and for size 4 an AUI of 0.41 was calculated (minimal coverage between 54 and 59\%). These values are comparable with our findings. Similar to our results, in this study, it was strongly advised to use whenever possible, the larger size Charité III TDRs.

The present study did not find an association between implantation asymmetry and clinical outcome or the occurrence of subsidence. A study of McAfee et al. [18] found that non-central implantation of the Charite TDR $(n=205$, follow-up 24 months), negatively affected clinical outcome and range of motion. No associations with the occurrence of subsidence were studied. Possibly, the effect of non-central implantation does not influence clinical outcome by subsidence or diminishes over time. 


\section{Study limitations and strengths}

The current study's main limitation is its retrospective nature. We were only able to report on the changes in AR and PBV between directly post-operative and at last followup, which was not a standardized interval. In addition, we were only able to report on eight out of the 32 patients with a revision of their TDR. Therefore, it was not possible to correlate the obtained threshold values for symptomatic subsidence, with the likelihood of a revision. The mean follow-up of 16.7 years is substantial and might explain the relatively large number of patients who were lost to follow-up, mainly caused by patients who had died or could not be retrieved. In only $15 \%$ of the patients, the direct post-operative radiographs were not available. Therefore, the number of patients included in this study is such that the outcomes may be considered valid and representative. Although the Charite III total disc replacement (TDR) is since 2012 no longer available on the market, the basic design features of many TDRs used today, are still very comparable and we think important lessons can be drawn for other designs as well. Subsidence is a recognized concern in the TDR surgery, and this is the first study to report on the association between the radiographic subsidence and clinical outcome. In addition, this study indicates that occurrence of symptomatic subsidence is related to the position and relative size of the TDR, which are factors that can be optimized by the surgeon preor intraoperatively.

Funding No funding was received for this work. The current study was approved by the Medical Ethics Committee METC Z (16-N-22) and registered at the Dutch Trial Registry (NTR5710).

\section{Compliance with ethical standards}

Conflict of interest All authors declare that they have no conflict of interest.

Informed consent Informed consent was acquired in all patients.

Open Access This article is licensed under a Creative Commons Attribution 4.0 International License, which permits use, sharing, adaptation, distribution and reproduction in any medium or format, as long as you give appropriate credit to the original author(s) and the source, provide a link to the Creative Commons licence, and indicate if changes were made. The images or other third party material in this article are included in the article's Creative Commons licence, unless indicated otherwise in a credit line to the material. If material is not included in the article's Creative Commons licence and your intended use is not permitted by statutory regulation or exceeds the permitted use, you will need to obtain permission directly from the copyright holder. To view a copy of this licence, visit http://creativecommons.org/licenses/by/4.0/.

\section{References}

1. Deyo RA, Gray DT, Kreuter W, Mirza S, Martin BI (2005) United States trends in lumbar fusion surgery for degenerative conditions. Spine (Phila Pa 1976) 30(12):1441-1445 (discussion 6-7)

2. Gillet $P(2003)$ The fate of the adjacent motion segments after lumbar fusion. J Spinal Disord Tech 16(4):338-345

3. Ha KY, Lee JS, Kim KW (2008) Degeneration of sacroiliac joint after instrumented lumbar or lumbosacral fusion: a prospective cohort study over 5-year follow-up. Spine (Phila Pa 1976) 33(11):1192-1198

4. Katz V, Schofferman J, Reynolds J (2003) The sacroiliac joint: a potential cause of pain after lumbar fusion to the sacrum. J Spinal Disord Tech 16(1):96-99

5. Kumar MN, Jacquot F, Hall H (2001) Long-term follow-up of functional outcomes and radiographic changes at adjacent levels following lumbar spine fusion for degenerative disc disease. Eur Spine J 10(4):309-313

6. Lee CK (1988) Accelerated degeneration of the segment adjacent to a lumbar fusion. Spine (Phila Pa 1976) 13(3):375-377

7. Park Y, Ha JW, Lee YT, Sung NY (2011) Cranial facet joint violations by percutaneously placed pedicle screws adjacent to a minimally invasive lumbar spinal fusion. Spine J Off J N Am Spine Soc 11(4):295-302

8. Umehara S, Zindrick MR, Patwardhan AG, Havey RM, Vrbos LA, Knight GW et al (2000) The biomechanical effect of postoperative hypolordosis in instrumented lumbar fusion on instrumented and adjacent spinal segments. Spine (Phila Pa 1976) 25(13):1617-1624

9. Martin BI, Mirza SK, Comstock BA, Gray DT, Kreuter W, Deyo RA (2007) Reoperation rates following lumbar spine surgery and the influence of spinal fusion procedures. Spine (Phila Pa 1976) 32(3):382-387

10. van den Eerenbeemt KD, Ostelo RW, van Royen BJ, Peul WC, van Tulder MW (2010) Total disc replacement surgery for symptomatic degenerative lumbar disc disease: a systematic review of the literature. Eur Spine J 19(8):1262-1280

11. Jacobs W, Van der Gaag NA, Tuschel A, de Kleuver M, Peul W, Verbout AJ et al (2012) Total disc replacement for chronic back pain in the presence of disc degeneration. Cochrane Database Syst Rev 9:CD008326

12. Siepe CJ, Zelenkov P, Sauri-Barraza JC, Szeimies U, Grubinger T, Tepass A et al (2010) The fate of facet joint and adjacent level disc degeneration following total lumbar disc replacement: a prospective clinical, $\mathrm{X}$-ray, and magnetic resonance imaging investigation. Spine (Phila Pa 1976) 35(22):1991-2003

13. Hedman TP, Kostuik JP, Fernie GR, Hellier WG (1991) Design of an intervertebral disc prosthesis. Spine (Phila Pa 1976) 16(6 Suppl):S256-S260

14. Punt IM, Visser VM, van Rhijn LW, Kurtz SM, Antonis J, Schurink GW et al (2008) Complications and reoperations of the SB Charite lumbar disc prosthesis: experience in 75 patients. Eur Spine $\mathbf{J}$ 17(1):36-43

15. Lee CS, Chung SS, Oh SK, You JW (2011) Significance of angular mismatch between vertebral endplate and prosthetic endplate in lumbar total disc replacement. J Spinal Disord Tech 24(3):183-188

16. Kitzen J, Schotanus MGM, van Kuijk SMJ, Jutten EMC, Kort NP, van Rhijn LW et al (2020) Long-term clinical outcome of the Charité III total lumbar disc replacement. Eur Spine J. https://doi. org/10.1007/s00586-020-06308-8

17. Lee CS, Lee DH, Hwang CJ, Kim H, Noh H (2014) The effect of a mismatched center of rotation on the clinical outcomes and flexion-extension range of motion: lumbar total disk replacement using mobidisc at a 5.5-year follow-up. J Spinal Disord Tech 27(3):148-153 
18. McAfee PC, Cunningham B, Holsapple G, Adams K, Blumenthal S, Guyer RD et al (2005) A prospective, randomized, multicenter Food and Drug Administration investigational device exemption study of lumbar total disc replacement with the CHARITE artificial disc versus lumbar fusion: part II: evaluation of radiographic outcomes and correlation of surgical technique accuracy with clinical outcomes. Spine (Phila Pa 1976) 30(14):1576-1583 (discussion E388-90)

19. Gstoettner M, Heider D, Liebensteiner M, Bach CM (2008) Footprint mismatch in lumbar total disc arthroplasty. Eur Spine J 17(11):1470-1475

20. Punt I, van Rijsbergen $M$, van Rietbergen $B$, Ito $K$, van Rhijn $L$, van Ooij A et al (2013) Subsidence of SB Charite total disc replacement and the role of undersizing. Eur Spine J 22(10):2264-2270

21. Yoder JH, Auerbach JD, Maurer PM, Erbe EM, Entrekin D, Balderston RA et al (2010) Augmentation improves human cadaveric vertebral body compression mechanics for lumbar total disc replacement. Spine (Phila Pa 1976) 35(9):E325-E331

22. Kitzen J, Vercoulen TFG, van Kuijk SMJ, Schotanus MGM, Kort NP, van Rhijn LW et al (2019) Long-term clinical outcome of two revision strategies for failed total disc replacements. Eur Spine J. https://doi.org/10.1007/s00586-019-06184-x

23. Dvorak J, Panjabi MM, Chang DG, Theiler R, Grob D (1991) Functional radiographic diagnosis of the lumbar spine. Flexion-extension and lateral bending. Spine (Phila Pa 1976) 16(5):562-571

24. Harrison DE, Harrison DD, Cailliet R, Janik TJ, Holland B (2001) Radiographic analysis of lumbar lordosis: centroid, Cobb, TRALL, and Harrison posterior tangent methods. Spine (Phila Pa 1976) 26(11):E235-E242

25. Tharmanathan P, Adamson J, Ashby R, Eldabe S (2012) Diagnosis and treatment of failed back surgery syndrome in the UK: mapping of practice using a cross-sectional survey. Br J Pain 6(4):142-152

Publisher's Note Springer Nature remains neutral with regard to jurisdictional claims in published maps and institutional affiliations. 